Available online at GSC Online Press Directory

GSC Biological and Pharmaceutical Sciences

e-ISSN: 2581-3250, CODEN (USA): GBPSC2

Journal homepage: https://www.gsconlinepress.com/journals/gscbps

(RESEARCH ARTICLE)

\title{
Evaluation of thyroid nodules on radiation-exposed workers
}

\author{
Yuyun Yueniwati * and Habiba Aurora \\ Radiology Department, Faculty of Medicine, Universitas Brawijaya Malang, Indonesia.
}

Publication history: Received on 13 October 2020; revised on 04 November 2020; accepted on 06 November 2020

Article DOI: https://doi.org/10.30574/gscbps.2020.13.2.0343

\begin{abstract}
Background. Ionizing radiation could cause negative effects on DNA molecules, which leads mutation and tumorigenesis. Thyroid gland is one of the most radiosensitive organ due to the great oxidative process on their physiological condition. Medical workers have been exposed to radiation during medical image acquisition. The relation between radiation and the increase of thyroid cancer incidence have been studied before, the discussion mostly explain the acute effect of radiation. The aim of this study is to describe the incidence of thyroid nodule on radiation-exposed worker.
\end{abstract}

Methods. The study was performed in 40 radiation-exposed workers with at least has 5 years working period. We examined using thyroid ultrasonography and blood level of T3, fT4 and TSH.

Result. The incidence of thyroid nodule in radiation-exposed worker is $37.5 \%$, which is higher among female (66\%) than in male (29\%). Based on the age distribution, most of the nodules were find in workers with age more than 35 years old. According to ultrasonography result and TIRADS scoring, $66.7 \%$ of the nodules were benign which categorize as TIRADS 1 and only 33\% of the nodules were categorize as moderately suspicious or TIRADS 4 .

Conclusion. Radiation-exposed workers have high risk to develop thyroid nodules. This study could be used as basic data to do further evaluation. It is important to perform thyroid screening periodically among them.

Keywords: Thyroid nodule; Radiation Exposed workers; Ultrasound.

\section{Background}

The dangers of ionizing radiation to human body have been observed since a long time ago. On normal cells, radiation can have damaging biological effects to human cells and tissues through its effects to the cells' DNA (1). The potential of biological and damaging effects of radiation depends on the quality and quantity of radiation, the absorbed dose, and the exposure condition. Biological effects of radiation consist of deterministic and stochastic effects. Deterministic effects have a dose threshold below which the exposure effect does not occur. Meanwhile, stochastic effects do not have a dose threshold. Stochastic effects are probabilistic and directly proportional to the absorbed dose. These effects' manifestation may be in the form of malignancy or genetic disorders (2). DNA molecules is the primary target of radiation. DNA mutation explains the induction of tumorigenesis as the result of radiation, for instance, the induction of AML1 on myelodysplastic syndrome and the induction of RET/PTC in papillary thyroid carcinoma (3) (4).

Thyroid gland is the biggest endocrinal gland which produces the thyroid hormones that have effects on the basal metabolic rate, protein synthesis, and various other effects, such as growth. Radiation causes oxidative stress on all

\footnotetext{
${ }^{*}$ Corresponding author: Yuyun Yueniwati

Radiology Department, Faculty of Medicine, Universitas Brawijaya Malang, Indonesia.

Copyright $(2020$ Author(s) retain the copyright of this article. This article is published under the terms of the Creative Commons Attribution Liscense 4.0.
} 
tissues. However, to thyroid gland, oxidative process greatly affects the synthesis of thyroid hormone. This is due to the majority of ROS (reactive oxygen species), especially hydrogen peroxide (H2O2), are produced by the thyroid on physiological condition. The presence of oxidative stress-owing to the ionizing radiation-will worsen the macromolecular damage, potentially leading to thyroid disorder and, eventually, cancer (5). The relationship between radiation exposure and the occurrence of thyroid cancer has been long studied; risks increase after having been exposed by average dose of more than 0.05-0.1 Gy (50-100 mGy) with latent period of 5-10 years before the thyroid cancer appears. Papillary thyroid carcinoma is a form of thyroid carcinoma most often diagnosed after radiation exposure (6).

Currently, many health workers have been exposed to radiation throughout numerous medical procedures. Authorized institution on radiation determine the minimum dose average allowed for professionals working with radiation. Most often, the problems complained by workers in radiology units are thyroid problems, hair loss, and eye diseases (7). The awareness and knowledge about the importance of radiation protection is needed for radiology workers to create a safe working atmosphere (8). International Agency for Research on Cancer (IARC) have conducted studies on more than 400,000 radiation workers in nuclear industries, with results showing little improvement on cancer risks even for lowdose cases and within the acceptable dose threshold. Therefore, it is essential to look out for radiation workers' health in various diagnostic and therapeutic departments (9). Up until now, only a handful of studies focus on the effect of ionizing radiation to radiation-exposed health workers. Existing research related to the effect of radiation have only been revolving around the acute impacts of ionizing radiation (10). This study served a purpose as a preliminary evaluation of disorder on thyroid gland-a radiosensitive organ-on radiation-exposed health workers.

\section{Methods}

This study was conducted from April to July of 2020, consisting of examinations on 40 radiographers with inclusion criteria of working for a minimum of 5 years. USG examination was carried out for evaluating thyroid gland and lymph nodes on the coli bilateral region. We measured the volume of thyroid gland while also evaluating the presence of cystic or solid lesions, which were then classified using the TIRADS system to determine the necessary follow-up actions. In addition, blood test was used to evaluate the level of T3, fT4, and TSH.

\section{Results and discussion}

From the 40 radiographers subjected to this study, a majority of which were at the age range of $41-45$ and $77.5 \%$ of them were male. Based on the duration work under exposure to radiation, a lot of them have been working for $6-10$ years (20\%) and 20-25 years (20\%). During the USG examination, 37.5\% of the examined radiographers displayed indications of thyroid nodules, while laboratory examination revealed only $5 \%$ showed abnormalities of TSH level and $20 \%$ showed an increase in their fT4 level. $100 \%$ of the examined radiographers had their T3 level within normal limit (Table 1).

Table 1 Data on Patients' Demography.

\begin{tabular}{|l|l|}
\hline Age (Years old) & Patient (n=40) [n (\%)] \\
\hline $26-30$ & 10 \\
\hline $31-35$ & 7.5 \\
\hline $36-40$ & 25 \\
\hline $41-45$ & 22.5 \\
\hline $46-50$ & 20 \\
\hline $51-55$ & 15 \\
\hline Range & $26-54$ Years Old \\
\hline Sex & 22.5 \\
\hline Female & 77.5 \\
\hline Male & \\
\hline Duration of Work under Radiation Exposure (Years) \\
\hline
\end{tabular}




\begin{tabular}{|l|l|}
\hline $5-10$ & 20 \\
\hline $11-15$ & 17.5 \\
\hline $16-20$ & 15 \\
\hline $21-25$ & 20 \\
\hline $26-30$ & 17.5 \\
\hline $31-35$ & 10 \\
\hline Range & $6-33$ Years \\
\hline Thyroid Nodule & \multicolumn{2}{|l|}{} \\
\hline Present & 37.5 \\
\hline Not Present & 62.5 \\
\hline TSH Level & \multicolumn{2}{|l|}{} \\
\hline Increased & 2.5 \\
\hline Normal & 95 \\
\hline Decreased & 2.5 \\
\hline T3 Level & \multicolumn{1}{|l|}{} \\
\hline Increased & 0 \\
\hline Normal & 100 \\
\hline Decreased & 0 \\
\hline FT4 Level & 20 \\
\hline Increased & 80 \\
\hline Normal & 0 \\
\hline Decreased & \multicolumn{1}{|l}{} \\
\hline
\end{tabular}

The minimum range of duration determined in this examination conformed to the result of previous studies arguing that the latent period resulting from ionizing radiation exposure is 5-10 years, which means the radiographers examined in this study have all passed the minimum time of latent period (6). As a result, no examinations were done on health workers with radiation exposure less than 5 years.

According to the data obtained, $37.5 \%$ of the examined radiographers displayed images of thyroid nodules with distribution based on sex, age, and duration of work under radiation exposure is displayed in Table 2. In a publication by Popoveniuc and Jonklass in 2012, the incidence of thyroid nodules increases along with age. This study revealed that radiation-exposed workers with thyroid nodules increased threefold above 35 years of age. In this study, as the age increases, the duration of radiation exposure also increases. However, based on the duration of exposure, there seemed to be no tendency on the increase of thyroid nodule as the radiation exposure duration increases. Further research is needed to better produce conclusion in regard to radiation exposure and the presence of thyroid nodules, by means of comparison with patients who are not exposed with radiation and a larger number of samples.

Several preceding journals presented evidences that thyroid nodules occur more often on women than men (11, 12). Based on the result of this study, the percentage of male patients with thyroid nodules is greater than that of female patients. However, bear in mind that the distribution of female patients is fewer than male patients. Therefore, the occurrence of thyroid nodules on female patients is still higher which showed $66 \%$ out of all the female patients. Whereas for the male patients, the figure only showed $29 \%$ out of all male patients. Looking at the comparison based on sex distribution, thyroid nodules is much more frequent in female patients than in male patients. 
Table 2 Description of Nodules based on Patient's Characteristics.

\begin{tabular}{|c|c|}
\hline Age (Years Old) & Patient $(n=15)[n(\%)]$ \\
\hline $26-30$ & \multirow{6}{*}{$\begin{array}{l}6.67 \\
0 \\
20 \\
26.67 \\
26.67 \\
20\end{array}$} \\
\hline $31-35$ & \\
\hline $36-40$ & \\
\hline $41-45$ & \\
\hline $46-50$ & \\
\hline $51-55$ & \\
\hline \multicolumn{2}{|c|}{ Exposure Duration (Years) } \\
\hline $6-10$ & \multirow{6}{*}{$\begin{array}{l}13.33 \\
20 \\
13.33 \\
6.67 \\
33.33 \\
13.33 \\
\end{array}$} \\
\hline $11-15$ & \\
\hline $16-20$ & \\
\hline $21-25$ & \\
\hline $26-30$ & \\
\hline $30-35$ & \\
\hline \multicolumn{2}{|l|}{ Sex } \\
\hline Male & 60 \\
\hline Female & 40 \\
\hline
\end{tabular}

Ultrasonography is a quick, easy, and safe examination for detecting thyroid nodules. Thyroid nodules are oftentimes found unintentionally during radiological examination, and most of them are benign nodules. Only 3-7\% of radiological nodules show indication of change towards malignancies. Ultrasonography examination is a sensitive modality in detecting thyroid nodules and the images produced by sonography examination result will help guide for follow-ups $(13,14)$. Results obtained from USG examination will then be categorized according to TI-RADS. TI-RADS or Thyroid Imaging Reporting and Data System is a risk stratification system for classifying thyroid nodules based on images acquired from ultrasonography. This system was introduced by the Committee of the American College of Radiology (ACR) in 2017, and divided thyroid nodules into five categories, from TR1 to TR5. Classification using TI-RADS and the diameter of nodules determine the ensuing management, which is biopsy, or follow-up with USG. In determining the scoring, TI-RADS evaluates nodules based on their composition, echogenicity, shape, boundary, and echogenic focus (15).

Table 3 Description of Nodules based on USG Result.

\begin{tabular}{|l|l|}
\hline Number of Nodules & Patients (n=15) [n (\%)] \\
\hline Solitary & 40 \\
\hline Multiple & 60 \\
\hline Location of Nodules & \\
\hline Unilateral & 40 \\
\hline Bilateral & 60 \\
\hline Size of Nodules & \multicolumn{1}{|l|}{} \\
\hline$<2 \mathrm{~cm}$ & 80 \\
\hline$>2 \mathrm{~cm}$ & 20 \\
\hline TI-RADS Classification & \multicolumn{1}{|l|}{} \\
\hline TR1 & 40 \\
\hline TR2 & 0 \\
\hline TR3 & 16.7 \\
\hline TR4 & 33.3 \\
\hline TR5 & 0 \\
\hline
\end{tabular}


Based on USG examination result, the majority of nodules fall into the 1st TI-RADS category, meaning that these nodules are benign nodules. Meanwhile, the remaining 33.3\% are categorized into TI-RADS 4 which means that they are moderately suspicious. On TI-RADS 4, follow-up is for nodules of more than $1.5 \mathrm{~cm}$ and FNAB is for nodules of more than $2.5 \mathrm{~cm}$. In 2020, El Gamal et al published a study discussing the relationship of thyroid nodules with malignancy. Based on nodule size, nodules with a size of 1.0-1.9 $\mathrm{cm}$ are more inclined towards malignant thyroid nodules than benign, until the size $2 \mathrm{~cm}$. Nodule growth of more than $2 \mathrm{~cm}$ no longer affect malignancy risks (16). 80\% of the nodule sizes in this study are less than $2 \mathrm{~cm}$, requiring further examination to determine the type of nodule.

\section{Conclusion}

This study displayed the presence of thyroid nodules in workers exposed to radiation, which is found more in female subjects than in male. Based on age, the appearance of nodules escalated at the age of more than 35 . Based on ultrasonography examination result, the majority of nodules fall into the benign category (TR1), though the remaining $33 \%$ were indicative of TR4 category which require additional histopathological examination. Further evaluations are needed by taking a larger number of samples concerning the relationship of nodule appearance with radiation exposure by considering the types of modalities, distance, and the use of radiation protection equipment.

\section{Compliance with ethical standards}

\section{Acknowledgments}

We are grateful to all who were participated in this research.

\section{Funding Source}

This work was supported by grants from Universitas Brawijaya Malang, Indonesia (Doctor Mengabdi program).

\section{Disclosure of conflict of interest}

The authors declare no competing interests.

\section{References}

[1] Burgio E, Piscitelli P. Ionizing Radiation and Human Health : Reviewing Models of Exposure and Mechanisms of Cellular. Int I Environ Res Public Health. 2018 2018; 1-13.

[2] Choudhary S. Deterministic and Stochastic Effects of Radiation. Canc Therapy \& Oncol Int J 2018; 12(2): 1-2.

[3] Shimura T, Yamaguchi I, Terada H, Kunugita N. Review Lessons learned from radiation biology : Health effects of low levels of exposure to ionizing radiation on humans regarding the Fukushima accident. J. Natl. Inst. Public Health 2018; 67(1): 115-22.

[4] Yueniwati Y, Yusefi K. Is Nasal Preparation Prior to Pre-FESS CT Scan Necessary ? A Clinical Trial, Pre-Post Test Design. Int J Pharm Res. 2020; (1): 2486-91.

[5] Rai G, Kumar A, Mahobiya P. the effect of radiation on thyroid gland. International Journal of Biology Research. 2018.

[6] Iglesias ML, Schmidt A, Ghuzlan A Al, Lacroix L. Radiation exposure and thyroid cancer: a review. Arch. Endocrinol. Metab2017; (10).

[7] Erkan I, Yarenoglu A, Yukseloglu EH, Ulutin HC. The investigation of radiation safety awareness among healthcare workers in an education and research hospital. Int I Radiat Res 2019, 17(3): 455-461

[8] Elnari MA, Noor JAE, Yueniwati Y. Assessment the Awareness and Knowledge Level about Radiation Protection : An Empirical Study on the Radiology Professionals of the Radiology Assessment the Awareness and Knowledge Level about Radiation Protection: An Empirical Study on the Radiology Professionals of the Radiology Departments, East Java Indonesia. 2016. IRJES; 5(9): 34-40.

[9] Ahmad IM, Abdalla MY, Moore TA, Bartenhagen L, Case AJ, Zimmerman MC. Healthcare Workers Occupationally Exposed to Ionizing Radiation Exhibit Altered Levels of Inflammatory Cytokines and Redox Parameters. Antioxidants (Basel) 2019 Jan 1;8(1):12.

[10] Keshtkar M, Saba V. Review 1-Application of Different methods for Reducing Radiation Dose to Breast during MDCT. LBiomed Phys Eng. 2018; 8(4): 341-346

[11] Jiang H, Tian Y, Yan W, Kong Y, Wang H, Wang A, et al. The Prevalence of Thyroid Nodules and an Analysis of Related Lifestyle Factors in Beijing Communities. Int I Environ Res Public Health. 2016 Apr; 13(4): 442.

[12] Geanina Popoveniuc JJ. Nodules Thyroid. Med Clin North Am. 2013; 96(2): 329-49. 
[13] Kaseh A El, Shayeb M Al. Incidental thyroid nodules an ultrasound screening of the neck region : prevalence \& risk factors. Clin. Pract. (2018) 15(5), 873-879

[14] Xie C, Cox P, Taylor N, Laporte S. Ultrasonography of thyroid nodules : a pictorial review. Insight Imaging. 2016; 77-86.

[15] A Middleton WD, Grant EG. Thyroid Imaging Reporting and Data System (TI-RADS): A User's Guide. Radiology. 2018; 287(1).

[16] El-gammal AS, E-balshy MA, Zahran KM. Relationship between thyroid nodule size and incidence of thyroid cancer. Menoufia Med J . 2019; 1142-8. 